\title{
Determining Factors in Measuring Consumators Trends for Consumption
}

\author{
PhD. Eriona Deda
}

Agricultural University of Tirana, Faculty of Economics and Agribusiness

Ass. Prof. Dr. Behxhet Brajshori

University of Prizren "Ukshin Hoti", Faculty of Economics

\section{Abstract}

In this paper we focused on defining factors that affect in consum and in consumer behaviour. The purpose of this paper is to address the impact of Inflation and disposable income to consum, between different periods of time taken in study. We will use the consumer price index for Albanian case, to measure Inflation's rates changes for a certain period of time, or changes in prices of goods and services included in market basket. The period that we have taken in study is from year period 2012 to 2016 , which 2015 is the base year period. The aim of this paper is to calculate the annual average of inflation rates and to analyse changes for each periods taken in the study. Also we are going to explain the relationsheep between inflation and other factors influencing in consum and consumators behaviors.

Keywords: Consume ,market basket, Inflation, Inflation rate, consumer price index

\section{Introduction}

In this paper we intend to highlight the factors that affect on consumers behavior for different products and services. We are going to analyze that, how can be effected consumer's behavior by changes in overall price or inflation rates level and other factors such as available income.

Also, based on some data that we have obtained from instad.gov.al, by calculating the annual average consumer price indices, to measure changes in inflation rates, we have calculated annual average of inflation rates that shows changes by period that is taken in study. The data related with annual average consumer price indices are taken for period 2012-2016.

We should analyze which groups have had more changes in the average inflation rate, and how have affected these changes in consumer behavior.

The market basket is classified in 12 main groups, according to EUROSTAT classification (Institute for Eurostatistics).

\section{Literature}

Through the literature review we will provide some examples of other authors who have used in their study similar thematic as in my study.

Here are some examples:

1. The study of inflation by Stanley Fischer in (1971) in his study with topic "Relative Shocks, Relative Price Variability, and Inflation". In his paper he was focused on the relation between inflation and relative price variability, which were discussed various explanations of a causal relation between inflation and relative price variability provideing estimates of the relative prices variability that can be attributed to monetary and fiscal policy and viewing that inflation may be a factor explaining poor performance of the United States and other industrial economies after 1973.

2. William R. Easterly and Michael Bruno in their research with topic, "Inflation Crises and Long-Run Growth". Their research was focused on the negatively relationsheep between growth and inflation, the data covers 136 countries over the $1960-94$ period.

3. Alexander Tsyplakov in his project with topic "The Links Between Inflation and Inflation Uncertainty at the Longer Horizon" The aim of his paper was to examine the Okun-Friedman hypothesis of the link between inflation and inflation uncertainty using historical international data on monthly CPI. The evidence obtained strongly supports Okun-Friedman 
hypothesis both in time dimension for most countries and across countries.

4. Aarstol, Michael in his article with topic "Inflation, inflation uncertainty, and relative price variability". The aim of his study was to determine relationship between inflation and variability of relative price changes (RPV) using the menu-costs model, Lucas-Barro signal-extraction model, and the Hercowitz-Cukierman extension of Lucas-Barro model. Results indicate that none of the three models nor their combination can entirely explain relationship between inflation and RPV.

\section{Research Methods}

In our study have used the annual average consumer price indices, which measures annual average changes in prices of goods and services. Also, the aim of this method is to see how annual average inflation rates has changed by years period of our study and how it affected consumption.

\subsection{Purpose}

The purpose of this paper is to make a comparison of annual average changes in inflation rates according to periods taken in our study, and to see how could affect an increase or decrease of average inflation rate in consumer behavior to buy products and services that we have included in the market basket groups.

\subsection{The research questions}

In which period of time taken in study there have been more fluctuations of the annual average inflation rate, and what are some of factors that may have caused these fluctuations.

\subsection{The data and choice}

In our paper, we used secondary data, which are focused on INSTAT publications, where have taken some data about the average consumer price indices for 12 main market basket groups.

The data were obtained for period 2012 to 2016 , and have calculated anual average inflation rates for each year taken in study.

\section{Analysis Result}

In the table below have calculated annual average consumer price indices for periods of our study, that is from year 2012 to 2016, which 2015 is the base year period.

Table 1. Annual average consumer price indices for each periods taken in study

Average CPI by main groups and period

(December 2015=100)

\begin{tabular}{|l|l|l|l|l|l|l|}
\hline COICOP & Average CPI by main groups & CPI 2012 & CPI 2013 & CPI 2014 & CPI 2015 & CPI 2016 \\
\hline 1 & Food, and non-alcoholic beverages & 94.66 & 97.27 & 97.45 & 99.96 & 102.73 \\
\hline 2 & Alcoholic bevereges and tobacco & 86.16 & 88.83 & 94.03 & 99.08 & 100.80 \\
\hline 3 & Clothing and footwear & 107.03 & 103.18 & 101.58 & 100.39 & 99.31 \\
\hline 4 & Rent, water, fuel and power & 98.84 & 99.91 & 100.73 & 100.43 & 100.48 \\
\hline 5 & Furniture household and maintenance & 99.81 & 100.55 & 99.69 & 99.57 & 100.17 \\
\hline 6 & Medical care & 104.30 & 104.47 & 100.78 & 100.29 & 100.70 \\
\hline 7 & Transport & 101.51 & 101.63 & 102.13 & 100.65 & 99.02 \\
\hline 8 & Communication & 98.98 & 99.46 & 99.11 & 100.61 & 100.18 \\
\hline 9 & Recreation and culture & 99.88 & 99.47 & 99.58 & 99.94 & 100.18 \\
\hline 10 & Education service & 84.60 & 85.85 & 88.84 & 96.67 & 100.16 \\
\hline 11 & Hotels, coffe-house and restaurants & 94.63 & 96.12 & 97.88 & 99.21 & 100.02 \\
\hline 12 & Goods and varios services & 94.71 & 94.32 & 100.61 & 100.15 & 101.18 \\
\hline & Total Average CPI by main groups & 97.09 & 97.59 & 98.53 & 99.75 & 100.41 \\
\hline
\end{tabular}

Source: INSTAT. (2016). Consumer price index, Average consumer price indices. [Online] Available: http://www.instat.gov.al/al/temat/\%C3\%A7mimet/indeksi-i-\%C3\%A7mimeve-t\%C3\%AB-konsumit/\#tab2 December,2016).

The consumer price index is used, to measure changes of inflation rates for a certain period of time or changes in prices of goods and services included in market basket. (Salko \& Dhuci, 2005)

Market basket is classified in 12 main groups, in accordance with EUROSTAT classification (Eurostat Institute). Where are given the annual averages of respective consumer price indexes in $\%$ for each of main market basked groups, according to year period taken in study. 
Table 2. Total annual average of inflation rates according to periods under study

\begin{tabular}{|l|l|l|l|l|l|l|}
\hline & & $\begin{array}{l}\text { Inflation } \\
\mathbf{2 0 1 2}\end{array}$ & $\begin{array}{l}\text { Inflation } \\
\mathbf{2 0 1 3}\end{array}$ & $\begin{array}{l}\text { Inflation } \\
\mathbf{2 0 1 4}\end{array}$ & $\begin{array}{l}\text { Inflation } \\
\mathbf{2 0 1 5}\end{array}$ & $\begin{array}{l}\text { Inflation } \\
\mathbf{2 0 1 6}\end{array}$ \\
\hline 1 & Food, and non-alcoholic beverages & -5.4 & -2.7 & -2.8 & 0.1 & 3.0 \\
\hline 2 & Alcoholic bevereges and tobacco & -13.9 & -11.2 & -5.3 & -1.0 & 1.2 \\
\hline 3 & Clothing and footwear & 7.0 & 3.2 & 2.0 & 0.5 & -0.8 \\
\hline 4 & Rent, water, fuel and power & -1.2 & -0.1 & 0.7 & 0.5 & 0.1 \\
\hline 5 & Furniture household and maintenance & -0.2 & 0.6 & -0.3 & -0.4 & 0.2 \\
\hline 6 & Medical care & 4.3 & 4.5 & 1.8 & 0.5 & 0.2 \\
\hline 7 & Transport & 1.5 & 1.7 & 3.3 & 1.3 & -1.5 \\
\hline 8 & Communication & -1.0 & -0.5 & -0.4 & -0.7 & -0.2 \\
\hline 9 & Recreation and culture & -0.1 & -0.5 & 0.5 & 0.3 & 0.3 \\
\hline 10 & Education service & -15.4 & -14.1 & -3.8 & -1.6 & 0.4 \\
\hline 11 & Hotels, coffe-house and restaurants & -5.4 & -3.9 & -1.3 & -0.7 & 0.0 \\
\hline 12 & Goods and varios services & -5.3 & -5.7 & -3.1 & -1.0 & 0.0 \\
\hline & Annual Mutual Inflation Change & -2.9 & -2.4 & -0.7 & -0.2 & 0.2 \\
& & & & & \\
\hline
\end{tabular}

Source: Salko \& Dhuci, 2005

In table 2, are presented the annual average inflation rates for 12 market basket groups, according to annual periods of study.

Regarding the total annual average of inflation rates, can be concluded that in 2016 total annual average of inflation rate is $0.2 \%$, which is higher compared to the other years taken in study that results with negative values of total annual average inflation rates, which means that there has been a decrease in total inflation rates, except 2016 period that has a low positive value of total annual average of inflation rate.

In overall relatet to the total annual average of inflation rates can estimate that inflation rates may considered as expected or foreseeable, and we can say that inflation rate is stable, because no significant changes occur on aggregate demand and supply of goods. If total avarege of inflation rate reach values from 2-3\%, we can say that inflation is acceptable and does not cause imbalance on aggregate demand and supply of goods.

\subsection{Analysis of changes in average inflation rates by main groups and for each period}

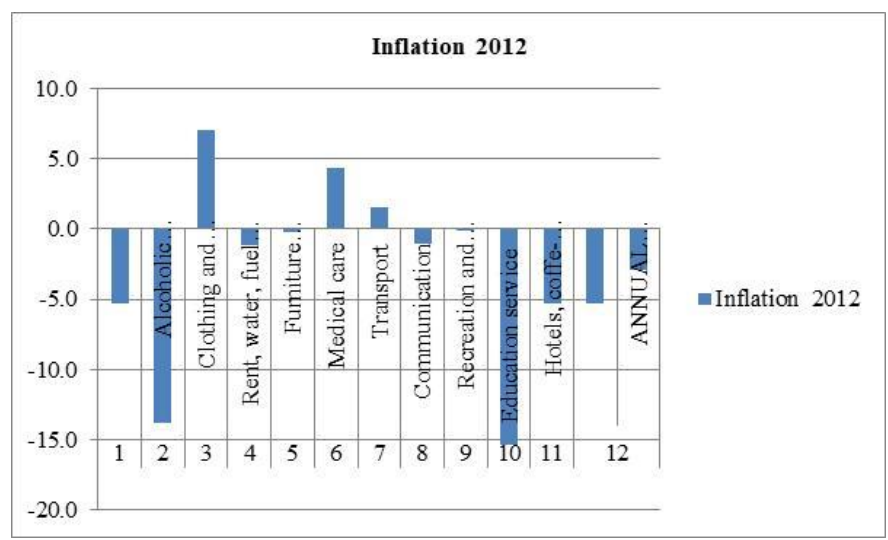

Chart 1. Changes in average of inflation rates by main groups for 2012

The chart shows that during 2012 annual average inflation rate has been variable, highest average inflation rate was achieved by "Clothing and Footwear" group with an average inflation rate of $7 \%$, followed by "Medical care" group with an 
average inflation rate of $4 \%$, and "Transport" group with average inflation rate 1.5\%. Inflation has had fluctuation throughout the year at lower and upper limits, marking an increase and fall in the average annual inflation rate.

In other groups, were observed significant price level movements, mainly with negative values of average inflation rate. This shows that for these groups have had a fall in annual average inflation rate, and at certain moments has influenced inflation as a whole.

Lowest level inflation rates were achieved by these groups : "Education service" with an average inflation rate of $-15.4 \%$ and by "Alcoholic bevereges and tobacco" with an average inflation rate of $-13.9 \%$.

Factors that have influenced inflation rate are classified as factors with a positive or negative impact, driven by demand or supply.

For 2012, the total annual average consumer price index reached value 97.09 in annual terms. Annual average inflation rate for 2012 is $-2.9 \%$

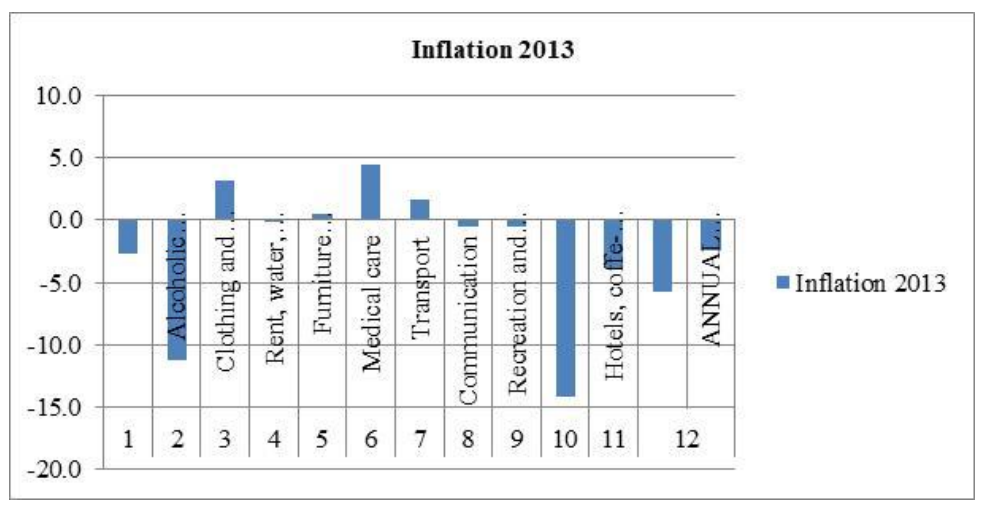

Chart 2. Changes in average of inflation rates by main groups for 2013

The chart shows that during 2013, highest annual average of inflation rate was achieved by "Medical care" group with an average inflation rate of $4.5 \%$, followed by "Clothing and Footwear" group with average inflation rate of $3.2 \%$. In other groups, were observed significant level movements, mainly with negative values of average inflation rate.

Indicating that for these groups have had a fall in annual average inflation rate.The lowest level of average inflation rates were achieved by these groups: "Education service" by average inflation rate of $-14.1 \%$ and "Alcoholic bevereges and tobacco" by average inflation rate of $-11.2 \%$.

For 2013, the total annual average consumer price index reached value 97.59 at annual level. Annual average inflation rate for 2013 is $-2.4 \%$

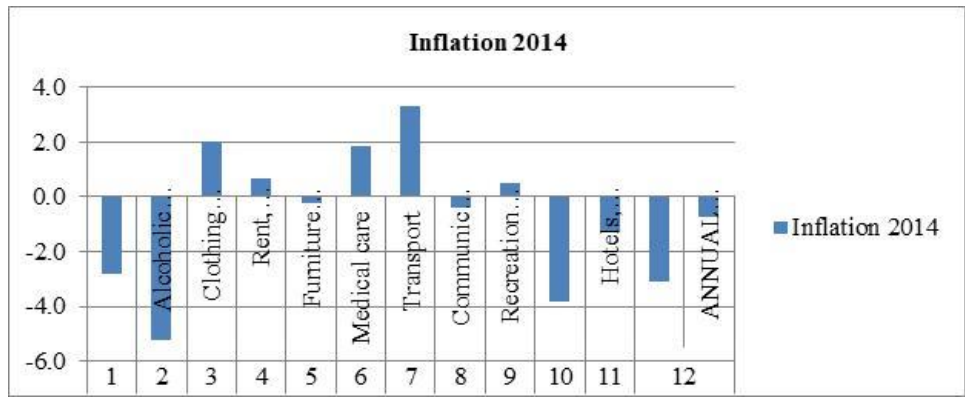

Chart 3. Changes in average of inflation rates by main groups for 2014 
The chart shows that during 2014, high levels and positive inflation rates were achieved by these groups: "Transport" with an average inflation rate of 3.3\%, "Clothing and footwear" with an average inflation rate of 2.0\%, "Medical care" by inflation rate of $1.8 \%$, and "Recreation and culture" with average inflation rate of $0.5 \%$. In other groups, were observed significant price level movements, mainly with negative values of average inflation rate.

Indicating that for these groups have had a fall in annual average inflation rate. The lowest inflation rates were achieved by these groups:

"Alcoholic bevereges and tobacco" with average inflation rate of $-5.3 \%$ and "Education service" group by average inflation rate of $-3.8 \%$.

For 2014, the total annual average consumer price index has reached level 98.53 , and total annual average inflation rate for 2014 is $-0.7 \%$

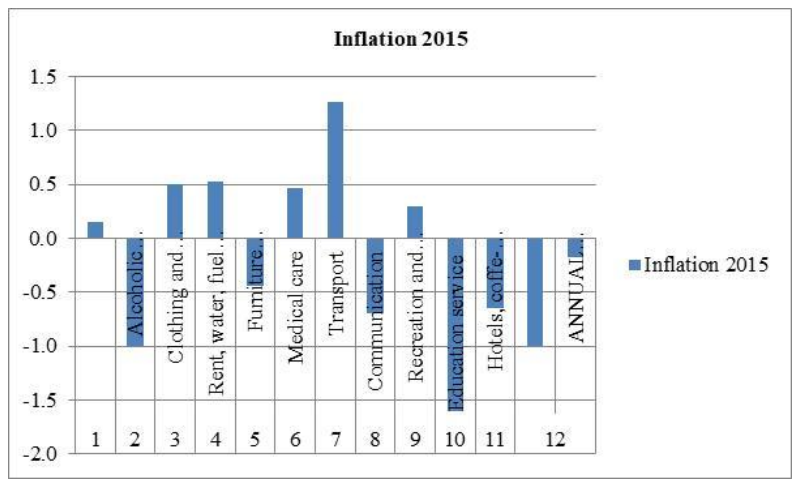

Chart 4. Changes in average of inflation rates by main groups for 2015

The chart shows that during 2015 , high levels and positive inflation rates were achieved by these groups: "Transport" with average inflation rate of $1.3 \%$, "Rent, water, fuel and power" and "Medical care" with respective average inflation rates $0.5 \%$, "Food, and non-alcoholic beverages" group with average inflation rate of $0.1 \%$. In other groups, were observed significant price level movements, mainly with negative values of average inflation rates.

Indicating that for these groups have had a fall in annual average inflation rate. Lowest inflation rates were achieved by these groups:"Education service" with an average inflation rate of $-1.6 \%$ and both "Alcoholic bevereges and tobacco", "Goods and varios services" groups, at respective average inflation rates of $-1.0 \%$.

For 2015, the total average consumer price index has reached 99.75 at annual level. Annual average inflation rate for 2015 is $-0.2 \%$

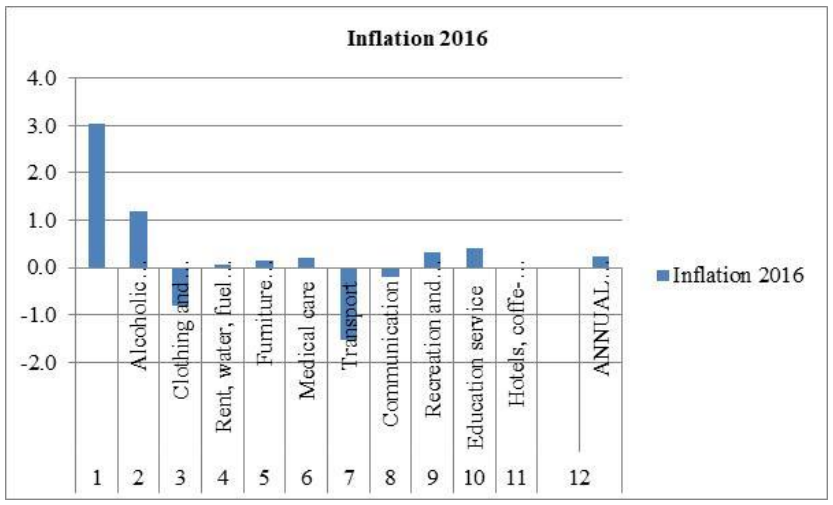


Chart 5. Changes in average of inflation rates by main groups for 2016

The chart shows that during 2016, higher levels of inflation were achieved by group "Food and non-alcoholic beverages" with an average inflation rate of 3.0\%, followed by "Alcoholic bevereges and tobacco", with average inflation rate of $1.2 \%$.

In other groups, were observed significant level movements, with positive and negative values of average inflation rate . It indicates that for these groups have had an increase and decrease of annual average inflation rate. Positive levels of inflation rates were achieved by these groups: "Rent, water, fuel and power", "Furniture household and maintenance", "Medical care", "Recreation and culture", "Goods and varios services". Lowest levels of inflation were achieved by these groups: "Transport" with average inflation rate of $-1.5 \%$ "Clothing and Footwear" with acorresponding average inflation rate of $-0.8 \%$.

For 2016, the total average consumer price index has reached value 100.41 at annual level. Annual average inflation rate for 2016 is $-0.2 \%$

\subsection{Income effect in consum}

Available income are another important factor that affects consumption. Consumption and incomes are linked to each other in right way, with increase of disposable income, consumption will increase. If disposable income will reduce the consumption is going to decrease..

Also disposable income directly affects consumer behavior. Consumers with high disposable income will consum and save more then consumers with low disposable income. In our paper we note that inflation is a very important indicator because in the economy of a country changes in inflation rate will have a direct impact on salaries of employees or on disposable income of consumers. So we can say that have a mutual relationship between inflation and disposable income, saving and consumption, stressing that the key role effecting in consumer behavior is inflation.

In our paper for the period taken in study, we can say that inflation is acceptable and does not cause imbalance on economic indicators.

\section{Conclusions}

The main factors that we have taken in analyse influencing consumer behavior are the changes in price of products and services and avaiable income.

The price of products and services is a very important factor influencing consumer behavior, which means according to (Nesturi, 2016) the law on demand if the price of products decreases, the readiness of consumers to buy increases. If the prices of products and services increase and consumers' readiness to buy will decreases with condition that other factors remain constant.

In our paper, we noted by comparing inflation for periods taken in the study, the highest and lowest levels of inflation have been achieved in year 2015. There are various factors that may have affected this rise in inflation,driven by the demand or the offer. However, generally we can assess controlled inflation levels and that hasn't had any significant growth to cause unbalance in macroeconomic indicators.

Incomes are a very important factor affecting consumer behavior because through available incomes consumers express ability to buy a product or service at a certain price, so we can say that income is a determinant factor of request.

\section{References}

[1] Easterly, R. W., \& Bruno, M. (1995). Inflation crises and long-run growth. World Bank Policy Research, [Online] Available:http://econ.worldbank.org/wbsite/external/extdec/extresearch/0,,contentMDK:20701015 pagePK:64214 825 piPK:64214943 theSitePK:469382,00.html (September 1995).

[2] Fischer, S. (1981). Relative shocks, relative price variability and inflation. US: Economic Studies Program, [ Online ] Available: https://www.brookings.edu/wp-content/uploads/1981/06/1981b_bpea_fischer_hall_taylor.pdf (1981).

[3] INSTAT. (2016). Average consumer price indices. [Online] Available: http://www.instat.gov.al/al /temat/\%C3\%A7mimet/indeksi-i-\%C3\%A7mimeve-t\%C3\%AB-konsumit/\#tab2 (December,2016). 
[4] Koka, M. (2012). Consumption and investment. In Macroeconomics (pp. 2-4). Tirana, Albania, Agricultural University of Tirana, Faculty of Economics and Agribusiness: [Online] Available: https://docs.google.com/viewer?a=v\&pid=sites\&srcid=dWJ0LmVkdS5hbHxtaW1vemEta29rYXxneDo1MzY3ZmQ xOWE4ZWZjOGFj (August,2012).

[5] Koka, M. (2012). Inflation. In Macroeconomics (pp. 2-14). Tirana, Albania, Agricultural University of Tirana, Faculty of Economics and Agribusiness: [Online] Available: https://docs.google.com/viewer?a=v\&pid=sites \&srcid=dWJ0LmVkdS5hbHxtaW1vemEta29rYXxneDo1MWJkY2I2YjI2MzQ5Mjgy (August, 2012).

[6] Michael, A. (1999, October 1). Inflation, inflation uncertainty, and relative price variability. Southern Economic Journal, $66(2)$.

[7] Nesturi, E. (2016). Demand and supply. In Microeconomics (pp. 8-13). Tirana, Albania, Agricultural University of Tirana, Faculty of Economics and Agribusiness: [Online] Available: https://docs.google.com/viewer?a=v \&pid=sites\&srcid=dWJOLmVkdS5hbHxlbnNOdXJpfGd4OjQzNDE5MGZhZjg3MjZjMDk (Jun,2016).

[8] Salko, D., \& Dhuci, O. (2005). Inflation and its impact (Vol. II). Tirana, Albania, Agricultural University of Tirana, Faculty of Economics and Agribusiness: "Dita 2000", 2005.

[9] Salko, D., \& Dhuci, O. (2005). Price indexes and their use (Vol. II). Tirana, Albania, Agricultural University of Tirana, Faculty of Economics and Agribusiness: "Dita 2000", 2005.

[10] Tsyplakov, A. (2010). The links between inflation and inflation uncertainty at the longer horizon. : [Online] Available: https://mpra.ub.uni-muenchen.de/26908/1/MPRA_paper_26908.pdf (2010). 